Purdue University

Purdue e-Pubs

CTRC Research Publications

Cooling Technologies Research Center

2014

\title{
System-Level Simulation of a Solar Power Tower Plant with Thermocline Thermal Energy Storage
}

\author{
S. Flueckiger \\ Purdue University \\ B. D. Iverson \\ Purdue University, bdiverson@byu.edu \\ Suresh V. Garimella \\ Purdue University, sureshg@purdue.edu \\ J.Pacheco \\ Purdue University
}

Follow this and additional works at: http://docs.lib.purdue.edu/coolingpubs

Flueckiger, S.; Iverson, B. D.; Garimella, Suresh V.; and Pacheco, J., "System-Level Simulation of a Solar Power Tower Plant with Thermocline Thermal Energy Storage" (2014). CTRC Research Publications. Paper 195.

http://dx.doi.org/http://dx.doi.org/10.1016/j.apenergy.2013.07.004

This document has been made available through Purdue e-Pubs, a service of the Purdue University Libraries. Please contact epubs@purdue.edu for additional information. 


\title{
System-Level Simulation of a Solar Power Tower Plant with Thermocline Thermal Energy Storage
}

\author{
Scott M. Flueckiger ${ }^{1}$, Brian D. Iverson ${ }^{2 * *}$, Suresh V. Garimella ${ }^{1 * * *}$, and James E. Pacheco ${ }^{2}$ \\ ${ }^{1}$ School of Mechanical Engineering \\ Purdue University \\ West Lafayette, IN 47907 \\ ${ }^{2}$ Solar Technologies Department \\ Sandia National Laboratories
}

Albuquerque, NM 87185

*Revised for publication in Applied Energy

**Now at Brigham Young University

***Author to whom correspondence should be addressed: Tel.: (765) 494-5621, Fax: (765) 494-

0539, E-mail: sureshg@ purdue.edu 


\begin{abstract}
A thermocline tank is a low-cost thermal energy storage subsystem for concentrating solar power plants that typically utilizes molten salt and quartzite rock as storage media. Longterm thermal stability of the storage concept remains a design concern. A new model is developed to provide comprehensive simulation of thermocline tank operation at low computational cost, addressing deficiencies with previous models in the literature. The proposed model is then incorporated into a system-level model of a $100 \mathrm{MW}_{\mathrm{e}}$ power tower plant to investigate storage performance during long-term operation. Solar irradiance data, taken from measurements for the year 1977 near Barstow, CA, are used as inputs to the simulation. The heliostat field and solar receiver are designed with DELSOL, while the transient receiver performance is simulated with SOLERGY. A meteorological year of plant simulation with a sixhour capacity for the thermocline tank storage yields an annual plant capacity factor of 0.531 . The effectiveness of the thermocline tank at storing and delivering heat is sustained above $99 \%$ throughout the year, indicating that thermal stratification inside the tank is successfully maintained under realistic operating conditions. Despite its good thermal performance, structural stability of the thermocline tank remains a concern due to the large thermal expansion of the internal quartzite rock at elevated molten-salt temperatures, and requires further investigation.
\end{abstract}




\section{Introduction}

Concentrating solar power (CSP) exploits the conversion of direct sunlight to hightemperature heat for large-scale power production. While it is a sustainable and environmentally benign source of energy, sunlight is an intermittent resource whose intensity is subject to planetary rotation, orbit, and atmospheric effects associated with weather conditions. Commercial facilities must therefore decouple solar collection from power production to meet consumer demand, independent of the prevailing conditions of solar irradiance. The generation of high-temperature heat in CSP plants provides built-in potential for the use of thermal energy storage systems to achieve this decoupling. While several design concepts exist for thermal energy storage, commercial storage systems must exhibit low cost, reliability, and effective delivery of heat for power production.

Thermal storage mechanisms involve sensible heat, latent heat, or thermochemical reactions. Sensible heat-based systems offer low energy densities but enable direct integration into the solar collection flow loop, avoiding rate-limiting steps inherent to the alternative phasechange or reaction-based approaches. Application of sensible storage is practical for traditional Rankine cycles, where heat addition to the working fluid occurs across a temperature rise. Current CSP plants featuring thermal energy storage therefore apply a sensible heat-based concept known as two-tank storage. In the case of a power tower plant employing this storage system, hot fluid (e.g., molten salt) exits the solar receiver during daylight and flows to a nominally isothermal hot tank. When power production is subsequently desired under nosunlight conditions, salt is extracted from this tank and sent to the plant power block for steam generation. While this system is simple and effective, mass balance in the collection loop 
requires a second tank upstream of the solar receiver to store the excess cold salt exiting the power block. This cold tank adds to the plant cost without providing any energy benefits.

The two-tank concept can be modified to save cost by storing the excess hot and cold molten salt inside a single tank volume, removing the physical redundancy of a second tank. Separation of the hot and cold fluid is retained in this thermocline tank via fluid buoyancy forces that help stratify the two isothermal regions along the vertical direction. At the interface of the hot and cold fluid, an intermediate layer of high temperature gradient develops, known as the thermocline or heat-exchange region. This sigmoid-shaped stratification is sustained over repeated storage cycles that involve flow reversal of the internal molten salt. During operation, the tank is energized or charged with hot salt entering at the top of the tank while cold salt is pumped out of the bottom. The heat-exchange region between the hot and cold salt travels downward during this charging process until the tank reaches its energy capacity, with the contents of the entire tank reaching the incoming hot salt temperature. For the discharge cycle, the heated tank pumps out the hot salt from the top, allowing cold salt to return at the bottom via a tubing manifold. This process continues until the heat-exchange region climbs to the top of the tank and the volume of available hot salt is exhausted.

Additional cost savings are realized by filling a majority of the tank interior with inexpensive granulated rock. This porous rock bed displaces a bulk of the (more expensive) molten salt volume and mitigates fluid mixing detrimental to the thermal stratification. Material selection for this filler is not trivial; the porous bed material must exhibit long-term compatibility with repeated temperature fluctuations in the surrounding salt. Pacheco et al. [1] investigated multiple filler candidates for compatibility with molten salt and reported quartzite rock and silica 
sand to be optimal selections due to their low cost, chemical inertness, and physical stability under several hundred thermal cycles with hot and cold salt.

A $170 \mathrm{MWh}_{\mathrm{t}}$ thermocline tank was installed at the historic Solar One pilot plant in Daggett, CA [2]. The tank operated from 1982 to 1986 and was filled with Caloria HT-43 mineral oil and granite rock. The use of mineral oil as the heat transfer fluid limited the storage system to a maximum temperature of $304^{\circ} \mathrm{C}$, a temperature suitable only for auxiliary steam generation. However, the thermocline tank satisfied its original design objectives. Sandia National Laboratories later constructed a small $2.3 \mathrm{MWh}_{\mathrm{t}}$ tank to validate the thermocline concept with molten salt and quartzite rock filler [1]. The concept was again determined to be a valid and feasible addition to solar power plants with a projected cost savings of $33 \%$ compared to the baseline two-tank storage design.

The elevated temperature and large physical scale of the thermocline tank have limited a majority of investigations to numerical analysis. A multidimensional computational fluid dynamics (CFD) model was developed by Yang and Garimella [3] to simulate mass, momentum, and energy transport inside a molten-salt thermocline tank. A two-temperature model resolved energy transport in both the molten-salt and solid filler regions. The governing conservation equations were discretized with the finite-volume method and solved with FLUENT, a commercial CFD package. With this model, the authors investigated thermocline performance during discharge with several different tank geometries and discharge powers. Well-insulated tanks exhibited improved performance at low Reynolds numbers and increased tank heights. For non-adiabatic tanks with significant external heat losses, discharge performance instead improved with increasing Reynolds number, due to the decreased fluid residence time inside the tank and reduced exposure to the heat loss condition [4]. Xu et al. [5] later modified the 
adiabatic model to perform a sensitivity study of material properties on storage performance. Flueckiger et al. [6] extended the non-adiabatic model to investigate thermal ratcheting phenomena in the thermocline tank wall.

Van Lew et al. [7] modeled energy transport inside a thermocline tank with the onedimensional Schumann equations. Corresponding analysis of the mass transport was omitted by assuming constant fluid density and velocity. A solution to the energy equations was obtained with the method of characteristics and required minimal computational times. For cyclic tank operation, the authors reported improved storage performance with reduced filler size and increased fluid velocity, and attributed these findings to the improved convective heat transfer between the fluid and rock. The authors also reported that axial heat conduction was negligible during tank operation, but omitted analysis of standby periods between the charging and discharging processes when fluid in the tank is stagnant.

Kolb [8] developed a system-level model of the $50 \mathrm{MW}_{\mathrm{e}}$ Andasol parabolic trough plant in TRNSYS to simulate and compare annual plant output between two-tank and thermocline storage systems. Simulation of the thermocline tank was limited to energy transport with a standard TRNSYS component, but modified to include thermal diffusion and external heat losses. The annual plant output with thermocline tank storage was reported to be near equivalent to the two-tank plant. However, this similarity was contingent on sliding-pressure operation in the power block, which is necessary to accommodate molten salt exiting the thermocline tank below the hot temperature limit.

Comparison of the various thermocline tank simulations in the literature illustrates a persistent tradeoff between detailed CFD models with high computing cost and simplified energy transport models with low computing cost. In the current study, the authors seek to eliminate 
this tradeoff with a new thermocline tank model that is both comprehensive and computationally inexpensive. Development of the proposed model and subsequent validation with experimental data is discussed in the next section. Thermocline tank performance is then investigated at a system level with a commercial-scale CSP plant model, informed by recorded sunlight data and real plant operating conditions. While system-level studies with thermocline tank storage were previously reported by Kolb [8], his analysis was limited to synthetic oil parabolic trough plants with indirect storage. The current study instead investigates a $100 \mathrm{MW}_{\mathrm{e}}$ power tower plant with molten-salt heat transfer fluid and direct integration of the thermocline tank within the solar collection loop. Discussion of the corresponding solar collector and power block models is included in later sections. The integrated plant model is subjected to an entire meteorological year of sunlight data measured near Barstow, CA in 1977. Plant capacity factor and storage effectiveness are monitored throughout the year to quantify the contribution of the storage system to power production as well as the long-term sustenance of vertical thermal stratification inside the thermocline tank.

\section{Thermocline Tank Model Development}

A schematic diagram of the thermocline tank concept is illustrated in Figure 1. The tank is operated with a commercial molten nitrate salt mixture $\left(60 \mathrm{wt} \% \mathrm{NaNO}_{3}, 40 \mathrm{wt} \% \mathrm{KNO}_{3}\right)$ as the heat transfer fluid. The salt is liquid above $220^{\circ} \mathrm{C}$; however, the enforced operating range is $300^{\circ} \mathrm{C}-600^{\circ} \mathrm{C}$ to avoid inadvertent salt freezing in the plant infrastructure. This temperature

span exceeds that of current power tower plants, which operate between $290^{\circ} \mathrm{C}$ and $565^{\circ} \mathrm{C}$, but is assumed to be achievable through advancements in solar receiver performance. Physical 
properties of the salt in the liquid phase are known functions of temperature (degrees Celsius) $[9,10]:$

$$
\begin{aligned}
& \rho_{l}=2090-0.636 T_{l} \\
& k_{l}=0.443+1.9 \times 10^{-4} T_{l} \\
& \mu_{l}=0.022714-1.20 \times 10^{-4} T_{l}+2.281 \times 10^{-7} T_{l}^{2}-1.474 \times 10^{-10} T_{l}^{3}
\end{aligned}
$$

The specific heat of the molten salt is relatively constant with temperature and is approximated to have a constant value of $1520 \mathrm{~J} / \mathrm{kg}-\mathrm{K}$. Over the operating temperature span, this value exhibits a maximum deviation of $1.7 \%$ versus reported data [10]. For the quartzite rock filler, density, specific heat, and thermal conductivity are all assumed constant: $2500 \mathrm{~kg} / \mathrm{m}^{3}, 830 \mathrm{~J} / \mathrm{kg}$ $\mathrm{K}$, and $5 \mathrm{~W} / \mathrm{m}-\mathrm{K}$, respectively $[3,11]$. The porosity of the quartzite rock bed is fixed at 0.22 based on past experimental observation [1].

Given the inherent molten-salt density variation with temperature, a thermocline tank cannot be treated as a control volume. The liquid level inside the tank rises when the tank is filled with hot salt and falls when the tank is filled with cold salt. Therefore, an additional volume of pure molten salt must be maintained above the quartzite rock to prevent dryout of the

porous region. Past thermocline studies in the literature have neglected the inclusion and influence of this "liquid heel" in order to achieve a tacit control volume condition for numerical simulation. In contrast, the current study includes simulation of both the porous region and the pure liquid heel, as discussed in the following sections.

\subsection{Porous region}

Fluid and solid energy transport in the porous region are governed by the following conservation equations [3]: 


$$
\begin{aligned}
& \frac{\partial\left[\varepsilon \rho_{l} C_{p, l}\left(T_{l}-T_{\mathrm{c}}\right)\right]}{\partial t}+\nabla \cdot\left[\rho_{l} \mathbf{u} C_{p, l}\left(T_{l}-T_{c}\right)\right]=\nabla \cdot\left(k_{e f f} \nabla T_{l}\right)+h_{i}\left(T_{s}-T_{l}\right) \\
& \frac{\partial\left[(1-\varepsilon) \rho_{s} C_{p, s}\left(T_{s}-T_{c}\right)\right]}{\partial t}=-h_{i}\left(T_{s}-T_{l}\right)
\end{aligned}
$$

Spatial discretization of the filler region is neglected as the temperature in each solid rock is assumed to be homogeneous. Thermal diffusion between the solid filler rocks is also assumed to be negligible due to inter-particle contact resistance. However, the thermal conductivity of the rock does influence thermal diffusion in the fluid region, and is represented with an effective thermal conductivity. This effective value is calculated with the Gonzo correlation [12]:

$$
k_{\text {eff }}=k_{l} \frac{1+2 \beta \phi+\left(2 \beta^{3}-0.1 \beta\right) \phi^{2}+\phi^{3} 0.05 \exp (4.5 \beta)}{1-\beta \phi}
$$

where $\phi=1-\varepsilon$ and $\beta=\left(k_{s}-k_{l}\right) /\left(k_{s}+2 k_{l}\right)$. Eqs. 4 and 5 are also coupled by interstitial forced convection between the molten salt and quartzite rock. This convection coefficient is calculated with the Wakao and Kaguei correlation [13]:

$$
\mathrm{Nu}_{i}=6(1-\varepsilon)\left[2+1.1 \operatorname{Re}^{0.6} \operatorname{Pr}^{1 / 3}\right]
$$

The length scale used in the definition of Reynolds number is the effective diameter of the granulated rock.

For simplification, the thermocline tank is assumed to be well-insulated and to experience laminar and plug flow throughout the filler bed (i.e., any maldistribution of molten salt entering from the tubing manifolds is negligible). As a result, Eq. 4 reduces to a one-dimensional formulation along the axial direction. The molten-salt and solid filler temperatures are also normalized with respect to the hot and cold temperature limits: 


$$
\Theta=\frac{T-T_{c}}{T_{h}-T_{c}}
$$

Energy transport in the porous region reduces to the following differential equations:

$$
\begin{aligned}
& \frac{\partial\left(\varepsilon \rho_{l} C_{p, l} \Theta_{l}\right)}{\partial t}+\frac{\partial\left(\rho_{l} \mathrm{u} C_{p, l} \Theta_{l}\right)}{\partial x}=\frac{\partial}{\partial x}\left(k_{e f f} \frac{\partial \Theta_{l}}{\partial x}\right)+h_{i}\left(\Theta_{s}-\Theta_{l}\right) \\
& \frac{\partial\left[(1-\varepsilon) \rho_{s} C_{p, s} \Theta_{s}\right]}{\partial t}=-h_{i}\left(\Theta_{s}-\Theta_{l}\right)
\end{aligned}
$$

As previously discussed, all material properties are either constant or known functions of temperature. The remaining variables include the fluid and solid temperatures as well as the fluid velocity (u) in the convection term of Eq. 9. With two equations and three unknowns, an additional relationship is needed to obtain a unique temperature solution. Yang and Garimella [3] previously reported an inherent relationship between the speed of the heat-exchange region and the velocity of the molten salt entering the filler bed:

$$
\mathrm{v}=\frac{\rho_{l, \mathrm{in}} C_{p, l}}{\varepsilon \rho_{l, \mathrm{in}} C_{p, l}+(1-\varepsilon) \rho_{s} C_{p, s}} u_{\mathrm{in}}
$$

However, this relationship between fluid velocity and the resulting vertical shift of the heatexchange region is not limited to the porous-bed inlet and can be reformulated for any bed location where molten-salt density and velocity are known. Eq. 11 is combined with an alternative formulation at an arbitrary axial location inside the bed to yield the following:

$$
u_{x}=\frac{\varepsilon \rho_{l, x} C_{p, l}+(1-\varepsilon) \rho_{s} C_{p, s}}{\varepsilon \rho_{l, \mathrm{in}} C_{p, l}+(1-\varepsilon) \rho_{s} C_{p, s}} \frac{\rho_{l, \mathrm{in}}}{\rho_{l, x}} u_{\mathrm{in}}
$$

Eq. 12 reveals an inherent relationship between the fluid density field and the velocity field inside the porous bed, independent of time. Thus the thermocline fluid velocity can be determined without an explicit calculation of mass or momentum conservation. 
Solution to the reduced-order energy transport model in the porous bed region is obtained via a finite-volume method. The transient term is discretized with a first-order implicit method. Spatial discretization of the convective flux term is accomplished with the quadratic flux limiter, a quasi-second-order local extrema diminishing scheme. Picard iteration is implemented to resolve the non-linearity in Eq. 9 as well as the interstitial convection coupling with Eq. 10. The resultant algebraic equations are then solved at each time step with a tridiagonal matrix algorithm written in C. Iterations at each time step proceed until the non-dimensional residual error reduces to less than $10^{-6}$.

Under a charge process, molten salt is supplied to the thermocline liquid heel at $600^{\circ} \mathrm{C}$. A portion of this salt then enters the underlying porous bed, as explained in the next section. Cold liquid exits the bottom of the tank, and is solved for with an outflow boundary condition. In the discharge process, the salt reverses direction and enters the bottom of the bed at $300^{\circ} \mathrm{C}$. An outflow condition is again used to solve the corresponding exit of hot salt from the top of the porous bed into the liquid heel. Thermal diffusion between the porous bed and pure liquid heel is represented with a Dirichlet boundary condition informed by the instantaneous heel temperature, as discussed in the next section. As previously stated, the tank top and side walls are assumed to be well-insulated and adiabatic. For simplicity, the bottom of the porous region is also assumed to be adiabatic.

\subsection{Liquid heel}

Variations in molten-salt density with temperature generate the potential for dryout of the thermocline porous bed. Dryout must be avoided during storage operations as it would reduce the available energy storage capacity of the granular bed and may also inhibit extraction of hot 
molten salt from the tank. A pure liquid heel is therefore maintained at the top of the thermocline tank to prevent dryout of the underlying porous region. In reality, the sigmoid temperature profile along the height of the porous region will extend into this additional volume when the tank approaches a fully-discharged state. However, the height of the heel is not fixed and varies in response to the internal energy content of the tank, prohibiting straightforward analysis with a finite-volume approach. As a conservation approximation, the liquid heel is instead assumed to be an isothermal mass. The mass and energy of the heel are known at each time step as an outcome of the porous region model and surrounding CSP component models, discussed in later sections. The mean temperature of the heel is then calculated from the moltensalt specific heat:

$$
T_{\text {heel }}=T_{c}+\frac{E_{\text {heel }}}{M_{\text {heel }} C_{p, l}}
$$

This heel temperature informs not only energy transport with the underlying porous region but also represents the temperature of salt available for steam generation in the CSP plant power block.

\subsection{Model validation}

The accuracy of the thermocline tank model is verified by comparing predicted results for a 2.3 $\mathrm{MWh}_{\mathrm{t}}$ molten-salt tank constructed by Sandia National Laboratories against experimental measurements [1]. The tank measured $6.1 \mathrm{~m}$ in height and $3 \mathrm{~m}$ in diameter, filled with a mixture of quartzite rock and silica sand to a bed height of $5.2 \mathrm{~m}$. The bed porosity was reported to be 0.22. The measured temperature distribution in the tank during a two-hour discharge process is plotted in Figure 2. The authors did not report a molten-salt flow rate or an initial temperature condition, which are needed inputs to a simulation of the tank. However, the heat-exchange 
region plotted in Figure 2 is observed to travel up the thermocline tank at a rate of $2 \mathrm{~m}$ per hour. Using Eq. 11, this travel rate for the heat-exchange region corresponds to cold molten salt entering the porous bed at a velocity of $0.436 \mathrm{~mm} / \mathrm{s}$. A linear curve is then fit to the earliest measured temperature profile plotted in Figure 2 to provide an initial temperature condition.

With this estimated inlet velocity and initial temperature profile, the tank discharge is simulated, and the predicted molten-salt temperatures are included in Figure 2 for comparison with the experimental data. This simulation is performed both with the established CFD model developed in a prior study [3] and with the reduced-order finite-volume model described in the sections above. The internal filler is approximated as a bed of quartzite rock with an effective diameter of $1.5 \mathrm{~cm}$. The reduced-order model is discretized with an axial cell length $(\Delta \mathrm{x})$ of 2.2 $\mathrm{cm}$ and a time step $(\Delta \mathrm{t})$ of 3 seconds. Temperature results with a finer cell length and time step of $1.1 \mathrm{~cm}$ and 2 seconds, respectively, agreed with the coarser discretization to within $0.3 \%$ and verified grid convergence. The molten-salt temperature results for both CFD and reduced-order thermocline modeling approaches are included in Figure 2. The instantaneous temperature profiles are seen to exhibit good agreement with the reported data throughout the entire two-hour discharge operation. As previously stated, temperature in each solid rock is assumed to be homogeneous (i.e., a lumped capacitance). The validity of this assumption is indicated by the Biot number of the quartzite rock:

$$
\mathrm{Bi}=\frac{\mathrm{Nu}_{i}}{36(1-\varepsilon)} \frac{k_{l}}{k_{s}}
$$

During the 2-hour discharge, the rock exhibits a maximum Biot number of 0.139. While this value exceeds the conventional limit of 0.1 for lumped capacitance, it should be noted that the local thermal non-equilibrium between molten-salt and quartzite is on the order of $1 \mathrm{~K}$. Given 
that the overall temperature span of the thermocline tank is greater than $100 \mathrm{~K}$, lumped capacitance is an acceptable assumption for the solid region.

It should be also noted that simulation with the reduced-order model is two orders of magnitude faster than the CFD model and did not require the use of a commercial software package. With a validated and low-cost model, study of the thermocline tank is now extended to the system level, in order to investigate the storage performance in response to actual sunlight data and typical solar power plant operation.

\section{System-Level Model Development}

Development of a system-level power plant model involves the integration of three separate component models - solar collection, energy storage, and power production. The additional components are explained in the following; all component models are sized to operate together as a $100 \mathrm{MW}_{\mathrm{e}}$ power tower plant. The current study assumes no storage bypass, so that all heat and mass transfer between solar collection and power production occurs through the thermocline tank.

\subsection{Steam Rankine cycle}

As previously mentioned, existing CSP plants achieve power production with a traditional steam Rankine cycle. Hot molten salt generates the necessary superheated steam through a series of heat exchangers (preheater, evaporator, and superheater). In the current study, the steam then travels through a Rankine cycle composed of a non-reheat turbine and a single open feedwater heater for deaeration of the working fluid. The design, illustrated in Figure 3, is taken from the power block operated at the Solar Two power tower plant [14]. 
At nameplate or rated conditions, superheated steam enters the turbine at a temperature and pressure of $538^{\circ} \mathrm{C}$ and $125 \mathrm{bar}(12.5 \mathrm{MPa})$, respectively (state 1). A portion of the steam (y) exits the first turbine stage and is sent to the feedwater heater at an intermediate pressure while the remaining steam enters a second turbine stage (state 2). The steam exiting this turbine (state $3)$ is condensed across the vapor dome at $0.1 \mathrm{bar}(10 \mathrm{kPa})$ and exits the condenser as saturated liquid (state 4). This saturated liquid is then pumped into the feedwater heater (state 5) and mixes with the first turbine stage exhaust. The mixture exits the feedwater heater as saturated liquid (state 6) and is again pumped to 125 bar (state 7). The water then enters the molten-salt heat exchangers and returns to the turbine inlet state as superheated steam. Pressure drops across the various heat exchanger elements are assumed to be negligible. Figure 4 shows the corresponding temperature-entropy diagram for the rated cycle operation. The turbine and pump machinery are both assumed to exhibit an isentropic efficiency of 0.9 at rated load, resulting in a gross first-law cycle efficiency of 0.4116. Parasitic power consumption within the solar plant requires an overdesign of the power block, fixed at $10.3 \%$ for the current study [15]. Therefore, a desired net work output of $100 \mathrm{MW}_{\mathrm{e}}$ requires a gross output of $111.5 \mathrm{MW}_{\mathrm{e}}$ and a corresponding heat input of $270.9 \mathrm{MW}_{\mathrm{t}}$ for steam generation.

In addition to the rated performance, the combination of the Rankine cycle with a moltensalt thermocline tank also allows for derated operation in response to any salt delivered from the tank at temperatures below the hot design limit of $600^{\circ} \mathrm{C}$. This reduction in exergy is carried through the corresponding steam generation and reduces the turbine inlet temperature. Power production is sustained so long as the thermodynamic cycle adjusts in response to the decrease in steam quality. Known as sliding-pressure operation, the cycle mass flow rates and pressures are both lowered to accommodate the reduced turbine temperature in this mode of operation. The 
pressure drop across each of the turbine stages exhibits the following relationship with variable mass flow rate [16]:

$$
\frac{\dot{m}^{2}}{\dot{m}_{0}^{2}}=\frac{p_{1}{ }^{2}-p_{2}{ }^{2}}{p_{1,0}{ }^{2}-p_{2,0}{ }^{2}}
$$

where $p_{1,0}$ and $p_{2,0}$ are the turbine pressures at rated conditions. The isentropic efficiencies of the turbine and pump machinery are also influenced by off-peak performance. Spelling et al. [17] characterized the derated turbine efficiency as a function of turbine speed and enthalpy change:

$$
\eta_{t}=\eta_{t, 0}-2\left(\frac{N}{N_{0}} \sqrt{\frac{\Delta h_{t, 0}}{\Delta h_{t}}}-1\right)^{2}
$$

For the current study, both turbine stages are assumed to be constant speed. For pump performance, Lippke [16] reported the following relationship between efficiency and mass flow rate:

$$
\frac{\eta_{p}}{\eta_{p, 0}}=2 \frac{\dot{m}}{\dot{m}_{0}}-\left(\frac{\dot{m}}{\dot{m}_{0}}\right)^{2}
$$

Additional assumptions are necessary to solve the remaining cycle state points for derated operation. The condenser pressure is fixed at 0.1 bar $(10 \mathrm{kPa})$ for all cycle conditions. The outflows of the condenser and feedwater heater are always at saturated liquid conditions. The amount of superheat at the turbine inlet is fixed at $210 \mathrm{~K}$. The preheater also maintains a fixed inlet temperature of $230^{\circ} \mathrm{C}$ via recirculation of saturated liquid $(\mathrm{x}=0)$ from the evaporator. The derated cycle operation is limited to $30 \%$ of the rated gross output, or $33 \mathrm{MW}_{\mathrm{e}}$. The steam turbine inlet temperature associated with this minimum derated condition is $463^{\circ} \mathrm{C}$ and the corresponding temperature-entropy diagram is included in Figure 4. 


\subsection{Steam generators}

As stated in the previous section, generation of steam with hot molten salt occurs by means of three heat exchangers: a preheater, evaporator, and superheater. At design conditions, molten salt enters the superheater at $600^{\circ} \mathrm{C}$ and exits the preheater at $300^{\circ} \mathrm{C}$. Water enters the preheater at $230^{\circ} \mathrm{C}$, converts to steam in the evaporator at $328^{\circ} \mathrm{C}$, and exits the superheater at $538^{\circ} \mathrm{C}$. The overall heat transfer coefficients for these heat exchangers are taken from the Solar Two power block [14] and are listed in Table 1. The individual thermal power required for each component is determined from the water vapor dome, and is also included in Table 1. The design surface area for the preheater and superheater are then determined from the log mean temperature difference (LMTD). For the heat exchanger with fluid streams undergoing phase change, i.e., the evaporator, the design surface area is determined using the NTU method. Discussion of these methods is provided in [18]. Figure 5 shows the temperature response of the molten salt and steam inside each of the heat exchangers as a function of the available surface area.

For derated operation at reduced temperatures, the overall heat transfer coefficient for each heat exchanger becomes a function of the adjusted molten-salt and steam mass flow rates [19]:

$$
\frac{U}{U_{0}}=\left(\frac{\dot{m}_{l}}{\dot{m}_{l, 0}}\right)^{0.8}\left(\frac{\dot{m}_{\mathrm{wat}}}{\dot{m}_{\mathrm{wat}, 0}}\right)^{0.8}\left(\frac{\dot{m}_{l, 0}^{0.8}+\dot{m}_{\mathrm{wat}, 0}{ }^{0.8}}{\dot{m}_{l}^{0.8}+\dot{m}_{\mathrm{wat}}^{0.8}}\right)
$$

The plant model also allows molten salt exiting the preheater at $300^{\circ} \mathrm{C}$ to recirculate upstream of both the superheater and the evaporator to prevent flow of any saturated mixture outside the

evaporator. A plot of the temperature response for $30 \%$ derated turbine output is included in Figure 5. The hot molten-salt temperature necessary for this minimum output is $473^{\circ} \mathrm{C}$; thus any 
molten salt below this temperature is not utilizable for power production and will not be discharged from the thermocline tank. It should also be noted that the required preheater surface area must decrease to sustain the desired exit salt temperature of $300^{\circ} \mathrm{C}$ during derated operation. This variable area could be implemented in practice with a shell and tube heat exchanger that includes a tubing manifold. For derated operation, valves in the manifold close a select number of tubes within the heat exchanger and reduce the surface area available for convection.

For combination with the thermocline tank model, the heat exchanger and Rankine cycle models are simplified with polynomial expressions determined from linear regression. These expressions are algebraic relationships between the molten-salt hot supply temperature, moltensalt flow rate in the steam generators, and the gross turbine output power, $W$ (when salt available from the thermocline tank is above $473^{\circ} \mathrm{C}$ ). The polynomial curve fits obtained from linear regression are listed below, and are specific to the current problem statement:

$$
\begin{aligned}
& \frac{W}{W_{0}}=-1.706\left(\Theta_{\text {heel }}\right)^{3}+4.406\left(\Theta_{\text {heel }}\right)^{2}-2.031\left(\Theta_{\text {heel }}\right)+0.3307 \\
& \frac{\dot{m}_{\mathrm{HX}}}{\dot{m}_{\mathrm{HX}, 0}}=-0.5976\left(\Theta_{\text {heel }}\right)^{3}+0.399\left(\Theta_{\text {heel }}\right)^{2}+1.431\left(\Theta_{\text {heel }}\right)+0.2325
\end{aligned}
$$

The temperature of the molten-salt liquid heel inside the thermocline tank (from which hot salt is delivered to the steam generators) therefore determines both the gross turbine output power and required mass flow rate of molten salt in the power block.

Prior to any daily turbine output being achieved, both the steam generators and the turbine must be conditioned for power production through a multistage process known as startup. This includes warming of the heat exchangers, synchronization of the turbine with the generator, and ramp-up to rated gross output. During the heat exchanger warming and turbine synchronization stage, the thermocline tank supplies hot molten salt to the power block in an 
amount equivalent to the minimum thermal input (30\% load), but with no work output. After synchronization is complete, the turbine initiates power production with a linear ramp-up to rated operation.

The required time intervals for these actions is dependent on the initial turbine temperature, which is itself a function of the length of time since the previous shutdown [20]. For simplicity, this temperature is classified under three states - hot, warm, and cold. The turbine is designated as hot for up to 12 hours after a shutdown, after which it degrades to a warm condition. After 72 hours of shutdown, the turbine further degrades to a cold condition. Table 2 lists the process times for each turbine temperature state.

\subsection{Solar collection}

For the current study, concentrating and harvesting of direct sunlight is assumed to be performed with a central receiver or power tower design. A field of dual-axis heliostats follows the position of the sun and reflects the direct normal irradiance (DNI) onto an elevated receiver. From the thermocline tank, molten salt enters the receiver at $300^{\circ} \mathrm{C}$ and exits at $600^{\circ} \mathrm{C}$. The corresponding mass flow rate of molten salt is then a function of the power incident on the receiver. In reality, some fluctuation in the exit temperature does result from the lag in the adjustment of the mass flow rate with varying DNI. However, these events were brief due to a combination of temperature feed-back control and irradiance feed-forward control [14] and are omitted from the present system study.

Both the heliostat field and solar receiver are sized with DELSOL [15], a power tower design tool developed by Sandia National Laboratories. For a defined solar multiple and receiver shape, DELSOL solves for the optimum heliostat field and then computes the 
corresponding solar collection efficiency as a function of solar position. Solar multiple is the ratio of sunlight collected at noon on summer solstice relative to the nameplate thermal input to the Rankine cycle and is fixed to 2.3 for the current study. The thermal rating of the solar receiver, $623 \mathrm{MW}_{\mathrm{t}}$, is the product of this multiple and the Rankine cycle heat input at rated load. The corresponding heliostat field includes $1,170,000 \mathrm{~m}^{2}$ of reflector area surrounding a tower of height $194.7 \mathrm{~m}$. The solar receiver atop this tower is an external cylinder design with a diameter of $21 \mathrm{~m}$ and a height of $18 \mathrm{~m}$. Sunlight data for the plant simulation are taken from measurements near Barstow, CA. Included in this dataset are DNI measurements at 15-minute intervals from January 1 to December 31, 1977. This particular dataset was selected for its excellent annual insolation $\left(2700 \mathrm{kWh}_{\mathrm{t}} / \mathrm{m}^{2}\right)$, high granularity, and prior application in other power tower studies [20]. The heat collected by the solar receiver in response to the heliostat field and meteorological sunlight data is determined with SOLERGY, a power tower performance model generated by Sandia National Laboratories [21]. At each 15-minute interval, SOLERGY calculates the current solar collection efficiency and then outputs the corresponding power absorbed by the molten salt traveling inside the solar receiver. This receiver performance is modeled for the entire year of operation, and is assumed to be independent of the thermocline tank and power block systems. Furthermore, the mass flow rate in the solar receiver is assumed to vary in response to the collected power such that the exiting salt temperature is maintained at $600^{\circ} \mathrm{C}$ :

$$
\dot{m}_{\mathrm{rec}}=\frac{P_{\mathrm{rec}}}{C_{p, l}\left(T_{h}-T_{\mathrm{rec}, \mathrm{in}}\right)}
$$




\subsection{Model integration}

In the current study, the molten-salt thermocline tank is desired to provide the power tower plant with six hours of thermal energy storage. The maximum energy capacity of the tank should clearly exceed this condition to accommodate simultaneous containment of salt at cold and transitional temperatures. Sizing of the storage system is informed by a previous design study of thermocline tanks published by the Electric Power Research Institute [22], which applied an approximate overdesign of $40 \%$ for the tank volume. The study also concluded that the molten-salt liquid level should not exceed 39 feet $(11.89 \mathrm{~m})$ to stay within the maximum bearing capacity of the soil with a typical foundation. The height of the model quartzite bed is therefore fixed to $11 \mathrm{~m}$ to provide additional volume for the pure liquid heel above the bed. With the given energy densities of the molten salt and quartzite rock, a thermocline tank diameter of $36.27 \mathrm{~m}$ is required to satisfy the requisite energy capacity and volumetric overdesign. The effective diameter of the quartzite rock granules inside the tank is assumed to be $1 \mathrm{~cm} \mathrm{[23].}$

Integrating the thermocline tank model with the additional component models previously described generates a system-level model of a $100 \mathrm{MW}_{\mathrm{e}}$ power tower plant. The individual models interact at the system level as follows. During daylight hours, molten salt picks up solar radiation incident on the receiver and is delivered to the thermocline tank heel. The amount of heat input available at each time step is obtained from the SOLERGY receiver analysis. When the thermocline tank contains enough energy to sustain two hours of steam generation in the heat exchangers, hot salt is sent to the power block to initiate turbine startup. After startup is complete, the turbine is set for rated power production. Cold salt exiting the power block either 
returns to the solar receiver or to the bottom of the tank, as dictated by mass balance in the solar collection loop.

It is again noted that no provision for a bypass loop is included between the solar receiver and the power block, and all heat and mass transport in the power plant is routed through the thermocline tank. The thermocline tank operating condition (charge, discharge, or standby) and corresponding salt flow direction is therefore dependent on the immediate disparity in moltensalt mass flow rate between the power block (Eq. 20) and the solar receiver (Eq. 21). For example, when the receiver provides hot salt at a faster rate than is necessary in the power block, the thermocline tank is charged with the excess. Conversely, when the power block requires more flow than the amount provided by the receiver, the tank undergoes a discharge to make up the difference. A standby condition with stagnant molten salt (i.e., no net flow inside the porous bed) occurs when the discharging tank is depleted of all usable energy.

For prolonged charge processes, the salt exiting the bottom of the thermocline tank will begin to increase in temperature as the transitional heat-exchange region reaches the tank floor. When this warmer salt enters the solar receiver, the receiver mass flow rate increases to maintain the exit hot temperature at $600^{\circ} \mathrm{C}$, governed by Eq. 21 . However, cold salt exiting the bottom of the thermocline tank is limited to a maximum allowable temperature of $400^{\circ} \mathrm{C}$ to prevent overcharging of the storage system. Above this temperature, the thermocline tank is declared to be at energy capacity and transitions to a forced standby condition. With no more available storage, the solar receiver can only collect enough energy to satisfy the Rankine cycle steam generation. Heliostats are defocused away from the receiver and some amount of sunlight available for collection must be forgone: this amount of energy is known as thermal energy discard. The forced tank standby persists until the solar receiver power output decays near 
sunset and the energy-saturated tank can then be discharged to sustain the rated power production.

Under ideal clear sky conditions on a given day, the thermocline tank would energize to its capacity, go into standby, and finally discharge near sunset following shutdown of the solar receiver. In reality, random cloud transients will lead to sporadic DNI losses during daylight hours. Therefore additional care must be taken in the operation of the thermocline tank to avoid chaotic flow direction changes and consequent wear on the turbine. In the operation considered in the current study, dispatch of hot molten salt from the thermocline tank to the power block is prohibited until the turbine is guaranteed to operate for at least two hours. Prior to turbine startup, the system model checks both the energy content of the tank as well as receiver performance in the immediate future (already known from the SOLERGY solution) to ensure that this condition on the turbine is satisfied. The authors assume that in practice, plant operators are capable of making similar near-term receiver predictions from weather forecasts. As a result, rapid on-off toggling of either the thermocline tank or the Rankine cycle is avoided.

\section{Results and Discussion}

\subsection{CSP plant performance with and without storage}

At the onset of the power plant simulation, the thermocline tank fillerbed and liquid heel are both initialized to the cold molten-salt temperature limit of $300^{\circ} \mathrm{C}$. The fillerbed geometry is discretized with a cell length of $2.2 \mathrm{~cm}$ (500 cells) and a time step of 3 seconds; grid independence at this resolution was already verified with the previous simulation of a small-scale thermocline tank. As stated before, the performance of the heliostat field and solar receiver is first simulated in SOLERGY using a meteorological year of sunlight data reported near Barstow, 
CA. The amount of power collected by the receiver then serves as an input to the integrated thermocline tank and power block models for each time step of simulation.

The resulting plant simulation provides an entire year of performance data for solar collection, storage, and power production. A subset of these results is provided in Figure 6, where results are shown for the solar receiver power, energy storage, and gross turbine output for five days centered on the summer solstice, June 19 to 23 . The daily plant performance represented in the figure is explained as follows. After sunrise, the heliostat field and solar receiver activate and the collected solar power increases from zero. This initial heat collected is sent to the thermocline tank. When the stored energy inside the tank is sufficient for steam generation, the power block undergoes startup procedures, after which the turbine reaches its rated output. As the day progresses, the collected power increases to the $623 \mathrm{MW}_{\mathrm{t}}$ rating of the solar receiver, with the excess energy collected being sent to the thermocline tank. Close to sunset, the receiver power begins to decrease until the solar collection system must shutdown for the night. The thermocline tank is then discharged to sustain turbine output into the night. When the thermocline tank energy nears depletion, colder molten salt is supplied to the steam generators and the turbine transitions to derated output until an eventual shutdown.

The receiver data plotted in Figure 6 exhibit consistent daily performance, corresponding to minimal cloud influence for the selected days. A cloud transient did occur on day 172 of the year, indicated by noise in the receiver power near sunset and an early turbine shutdown relative to the other days. Also of interest is the repeated step decrease in the receiver power that occurs near sunset for the other days plotted in the figure. This reduction occurs when the solar receiver has collected enough excess thermal energy to saturate the thermocline tank, marked by molten salt exiting the bottom of the thermocline tank at $400^{\circ} \mathrm{C}$. As previously discussed, the tank goes 
into standby and the solar receiver can only collect thermal energy for steam generation, deviating from the receiver performance predicted by SOLERGY. This deviation quantifies the amount of thermal energy lost due to the lack of additional storage capacity. It should be noted that an economically optimized plant may have a storage system which discards some energy during the peak of the summer, but is heavily utilized during the rest of the year.

For a seasonal perspective, the plant capacity factor is calculated for each month and plotted in Figure 7. Capacity factor is the ratio of total turbine output over time to the theoretical maximum corresponding to constant output at rated load:

$$
\text { Capacity factor }=\frac{1}{W_{0}} \frac{\int_{\text {month }} W(t) d t}{\int_{\text {month }} d t}
$$

Monthly capacity factor is largest in the summer due to the seasonal variation in DNI available for collection, with a maximum value of 0.696 observed for July. With respect to the entire year, the power tower plant generates a total net output of $465.4 \mathrm{GWh}_{\mathrm{e}}$ and exhibits an annual capacity factor of 0.531 . The overall solar-to-electric efficiency of the power tower plant is defined as the ratio of the net work output to the theoretical maximum amount of sunlight collected (annual solar resource $\times$ total heliostat area), and achieves a value of 0.147 .

The contribution of the thermocline tank to plant performance is observed by repeating the simulation of the current power tower plant, but without a thermal energy storage system. The corresponding monthly capacity factors without storage are included in Figure 7 . As expected, absence of energy storage results in a significant drop in monthly capacity factor relative to the case with a thermocline tank. Year-long operation without storage reduces the annual capacity factor to 0.273 from 0.531 and the solar-to-electric efficiency to 0.076 from 0.147. The simulated thermocline tank was able to store over eight hours of useable heat during 
operation, which exceeded the originally desired six hours of storage. Thus the $40 \%$ overdesign for the tank size applied from the EPRI design study is shown to be larger than necessary, under the assumptions of the present work.

\subsection{Thermocline tank performance}

While the capacity factor reveals the impact of the thermocline tank over time, the usefulness of the thermal energy that passes through the storage subsystem for steam generation is quantified by the storage effectiveness, defined as the ratio of utilizable heat delivered from the tank to the maximum heat available:

$$
\varepsilon_{\text {tank }}=\frac{\int_{\text {month }} \dot{m}_{\mathrm{HX}} C_{p, l}\left(T_{\text {heel }}-T_{c}\right) d t}{\int_{\text {month }} P_{\text {rec }} d t+E_{\text {init }}}
$$

Utilizable heat refers to the available molten salt at sufficient temperature (exergy) for steam generation. The maximum available heat is the total amount of thermal energy delivered to the tank as hot molten salt from the solar receiver plus the initial energy content inside the tank. The monthly storage effectiveness values are plotted in Figure 8. The effectiveness remains above 99\% throughout the year, indicating that over $99 \%$ of thermal energy delivered to the tank from the solar receiver each month is later recovered for steam generation.

The excellent effectiveness of the thermocline tank is attributed to the regular (daily) and consistent use of the stored energy during operation, as indicated by the short time duration of standby periods when flow is stagnant inside the tank. During the year-long plant simulation, the tank experienced 615 separate instances of standby, of which $98.2 \%$ were less than 24 hours in duration. This indicates that the tank was operated either in charge or discharge mode on a daily basis throughout the meteorological year. The benefit of this daily operation is a limited 
residence time of hot molten salt inside the thermocline tank, mitigating the extent of thermal diffusion between the hot salt and the underlying cold salt. Thus for the diurnal cyclic behavior of thermoclines in solar plants, factors that would be detrimental to maintaining thermal stratification inside the tank and would inhibit storage performance over long-term application were found not to play a significant role over the chosen year with the DNI data for Barstow, CA. The thermocline tank is therefore concluded to be a viable thermal energy storage option for use in a solar power plant under such conditions.

The impact of the thermocline tank on power production is a function of its size and energy storage capacity. As previously discussed, thermal energy discard occurs when the thermocline tank becomes saturated with hot salt and is unable to store additional heat. Figure 8 includes a plot of thermal energy discarded each month, normalized with respect to the amount of sunlight available for collection. As with the plant capacity factor, thermal energy discard displays a strong seasonal dependence corresponding to the variation of DNI received. Winter months receive the least amount of sunlight and thus do not exhibit saturation of thermocline tank on a regular basis. In contrast, summer months experience frequent saturation and exhibit the largest amount of thermal energy discard. During the year, a total of 223 days experience energy saturation of the thermocline tank. The annual thermal energy discard associated with this saturation and subsequent heliostat defocusing is $176 \mathrm{GWh}_{\mathrm{t}}$ or $13.7 \%$ of the total energy collected by the solar receiver.

An optimal amount of thermal energy discard likely exists for a given solar power plant and energy storage system. If storage saturation and thermal energy discard occurs on a neardaily basis, the storage volume is likely undersized relative to the solar collection system, and this reduces the potential revenue of the solar plant. On the other hand, if thermal energy discard 
is never observed, the storage volume may be oversized and carry an excessive capital cost. Further investigation and optimization of the thermocline tank is therefore needed to quantify trade-offs in plant cost and annual revenue as a function of tank size.

The validity of the adiabatic tank wall assumption made in the present simulation is assessed by estimating the annual heat loss relative to the total amount of energy delivered to the tank from the solar receiver. The EPRI thermocline tank design study proposed mineral wool insulation $(\mathrm{k}=0.2 \mathrm{~W} / \mathrm{m}-\mathrm{K})$ at a thickness of 23 inches $(0.584 \mathrm{~m})$ for the tank [22]. The annual average temperature and wind speed in Barstow, CA in 1977 were $20.1^{\circ} \mathrm{C}$ and $4.94 \mathrm{~m} / \mathrm{s}$, respectively. For the maximum tank temperature of $600^{\circ} \mathrm{C}$, this external boundary condition generates an average convection heat loss of $203 \mathrm{~kW}$ through the mineral wool. The annual energy loss due to this convection is $1775 \mathrm{MWh}_{\mathrm{t}}$, or $0.138 \%$ of the total hot energy supplied to the thermocline tank from the solar receiver over the year. Given this very low percentage of expected loss, the original adiabatic tank wall assumption is deemed to be acceptable.

\subsection{System model comparison}

In addition to solar receiver performance, thermal energy storage and power production may also be modeled in SOLERGY. It is of interest to compare the simulated plant output from the current study with predictions from SOLERGY. Table 3 includes the annual outputs of the $100 \mathrm{MW}_{\mathrm{e}}$ power tower plant as predicted by the current study, along with SOLERGY results for both two-tank and thermocline storage systems of equivalent size. As seen in the table, SOLERGY predicts identical plant performance for either the two-tank and thermocline tank storage options. Comparison of the current study and the SOLERGY simulation also shows reasonable agreement, exhibiting a $2.34 \%$ difference in annual net turbine output. This 
difference may be attributed to the lack of molten-salt temperature control in the thermocline tank sub-model implemented in SOLERGY. In the current study, the temperature of salt leaving the bottom of the tank is limited to $400^{\circ} \mathrm{C}$ to avoid compromising the heat-exchange region, but this prevents the tank from reaching its maximum energy capacity. In contrast, SOLERGY does not consider such temperature limits and thus overpredicts the thermal energy storage performance in a thermocline tank. This added capacity manifests as greater power production and explains the somewhat larger annual turbine output in Table 3.

It should be noted that SOLERGY and the current system model both apply a sunfollowing control, which means the turbine is activated whenever sufficient energy is available from storage. In reality, the economic value of electricity is a function of variable time-of-day sale prices and will influence the choice of when the turbine is operational. An alternative plant control strategy would be to delay power production until the most lucrative hours of the day (e.g., weekday afternoons) in order to maximize the annual revenue. However, delaying power production may then lead to an increased occurrence of storage saturation and related thermal energy discard. This potential trade-off between maximizing power production and maximizing revenue is another area of further investigation.

\subsection{Thermocline structural stability}

Along with long-term thermal reliability, the thermocline tank must also exhibit structural stability in response to the repeated cycling during the charge-discharge cycles with hot and cold salt. The tank is also packed with quartzite rock; such quartz-based materials exhibit a change in crystal structure near $573^{\circ} \mathrm{C}$. As this inversion point and the corresponding volumetric expansion are within the applied molten-salt operating temperature range, heating the tank to the maximum 
hot temperature may lead to large hoop stresses in the surrounding tank wall. Previous structural models for thermocline tanks [6] did not operate above this critical temperature and may not be applicable. Experimental observation as well as further study of granular mechanics inside the thermocline tank is needed to ensure that the tank wall can sustain this quartzite phase change.

To increase safety, the dual-media thermocline tank concept can also be modified either with lower maximum operating temperatures or by use of alternative filler materials. Filler selection for the solid rock calls for both low cost and physical stability under repeated thermal cycling. In addition to quartzite, Pacheco et al. [1] reported successful application of iron ore taconite pellets with molten salt. However, physical property data for taconite are not readily available in the literature and require further study. Additional materials not considered in [1] should also be explored.

\section{Conclusions}

A numerical model for molten-salt thermocline tank operation has been developed to provide accurate simulation of mass and energy transport at low computing cost and without reliance on commercial CFD software. The thermal model is integrated into a system-level simulation of a $100 \mathrm{MW}_{\mathrm{e}}$ power tower plant to assess thermocline tank performance under realistic and long-term operating conditions. Operation of the plant model is informed by a meteorological year of sunlight data recorded near Barstow, CA in 1977. The molten-salt thermocline tank, sized to provide six hours of thermal energy storage, increased the annual plant capacity factor to 0.531 with excellent year-long storage effectiveness exceeding $99 \%$. This good performance results from the regular and consistent utilization of the stored energy in the tank during year-long plant operation, limiting the residence time of hot salt inside the tank and 
the corresponding loss of thermal stratification that would result. Comparison of the model developed in this work with the results from SOLERGY showed excellent agreement. The $2.34 \%$ difference observed between the results for annual turbine output is attributed to the absence of temperature control in the SOLERGY thermocline tank model, which results in overprediction of storage performance. Additional study is needed to assess the optimum tank size that balances the solar collection system size with the economic impact of turbine delay on maximum hourly electricity prices.

Even if long-term thermal stability is achieved, structural integrity of the thermocline tank remains a design concern due to the large volumetric expansion of the quartzite rock at elevated molten salt temperatures relative to the surrounding tank wall. Further investigation is needed to determine the maximum safe operating temperatures for quartzite rock and also to identify suitable alternative, non-quartz filler candidate materials.

\section{Acknowledgements}

The authors acknowledge Brian D. Ehrhart for assistance with use of models in DELSOL and SOLERGY. 


\section{References}

[1] J. E. Pacheco, S. K. Showalter, W. J. Kolb. Development of a molten-salt thermocline thermal storage system for parabolic trough plants. ASME J Sol Energy Eng 2002;124:153-9.

[2] L. G. Radosevich. Final report on the power production phase of the 10MWe solar central receiver pilot plant, SAND87-8022. Sandia National Laboratories; 1988.

[3] Z. Yang, S. V. Garimella. Thermal analysis of solar thermal energy storage in a molten-salt thermocline. Sol Energy 2010;84:974-85.

[4] Z. Yang, S. V. Garimella. Molten-salt thermal energy storage in thermoclines under different environmental boundary conditions. Appl Energy 2010;87:3322-9.

[5] C. Xu, Z. Wang, Y. He, X. Li, F. Bai. Sensitivity analysis of the numerical study on the thermal performance of a packed-bed molten salt thermocline thermal storage system. Appl Energy 2012;92:65-75.

[6] S. Flueckiger, Z. Yang, S. V. Garimella. An integrated thermal and mechanical investigation of molten-salt thermocline energy storage. Appl Energy 2011;88:2098-105.

[7] J. T. Van Lew, P. Li, C. L. Chan, W. Karaki, J. Stephens. Analysis of heat storage and delivery of a thermocline tank having solid filler material. ASME J Sol Energy Eng 2011;133:021003.

[8] G. J. Kolb. Evaluation of annual performance of 2-tank and thermocline thermal storage systems for trough plants. ASME J Sol Energy Eng 2011;133:031023.

[9] D. A. Nissen. Thermophysical properties of the equimolar mixture NaNO3-KNO3 from 300C to 600C. J Chem Eng Data 1982;27:269-73.

[10] J. E. Pacheco, M. E. Ralph, J. M. Chavez, S. R. Dunkin, E. E. Rush, C. H. Ghanbari, et al. Results of molten salt panel and component experiments for solar central receivers, SAND94-2525. Sandia National Laboratories; 1995.

[11] J. Cote, J.-M. Konrad. Thermal conductivity of base-coarse materials. Can Geotech J 2005;42:61-78.

[12] E. E. Gonzo. Estimating correlations for the effective thermal conductivity of granular materials. Chem Eng J 2002;90:299-302.

[13] N. Wakao, S. Kaguei. Heat and Mass Transfer in Packed Beds. New York: Gordon Beach; 1982.

[14] J. E. Pacheco. Final test and evaluation results from the Solar Two project, SAND20020120. Sandia National Laboratories; 2002. 
[15] B. L. Kistler. A user's manual for DELSOL3, SAND86-8018. Sandia National Laboratories; 1986.

[16] F. Lippke. Simulation of the part-load behavior of a 30 MWe SEGS Plant, SAND95-1293. Sandia National Laboratories; 1995.

[17] J. Spelling, M. Jocker, A. Martin. Thermal modeling of a solar steam turbine with a focus on start-up time reduction. ASME J Eng Gas Turbines Power 2012;134:013001.

[18] F. P. Incropera, D. P. DeWitt. Fundamentals of Heat and Mass Transfer. 5th ed. John Wiley \& Sons; 2002.

[19] A. M. Patnode. Simulation and performance evaluation of parabolic trough solar power plants. MSME Thesis. University of Wisconsin-Madison, 2006.

[20] G. J. Kolb. An evaluation of possible next-generation high-temperature molten-salt power towers, SAND2011-9320. Sandia National Laboratories; 2011.

[21] M. C. Stoddard, S. E. Faas, C. J. Chiang, J. A. Dirks. SOLERGY, SAND86-8060. Sandia National Laboratories; 1987.

[22] Electric Power Research Institute. Solar thermal storage systems: preliminary design study, 1019581. EPRI; 2010.

[23] S. M. Flueckiger, S. V. Garimella. Second-law analysis of molten-salt thermal energy storage in thermoclines. Sol Energy 2012;86:1621-31. 


\section{Nomenclature}

Bi Biot number, $\mathrm{Bi}=\frac{\mathrm{Nu}_{i}}{36(1-\varepsilon)} \frac{k_{l}}{k_{s}}$

$\mathrm{C}_{\mathrm{p}} \quad$ specific heat, $\mathrm{J} / \mathrm{kg}-\mathrm{K}$

d solid filler size, $\mathrm{m}$

E liquid heel energy, J

h enthalpy, $\mathrm{J} / \mathrm{kg}$

$\mathrm{h}_{\mathrm{i}} \quad$ interstitial heat transfer coefficient, $\mathrm{W} / \mathrm{m}^{3}-\mathrm{K}$

$\mathrm{k}$ thermal conductivity, W/m-K

$\dot{\mathrm{m}}$ mass flow rate, $\mathrm{kg} / \mathrm{s}$

M liquid heel mass, $\mathrm{kg}$

$\mathrm{N} \quad$ turbine blade speed, rpm

$\mathrm{Nu}_{\mathrm{i}} \quad$ Nusselt number, $\mathrm{Nu}_{i}=\frac{h_{i} d^{2}}{k_{l}}$

$\mathrm{p} \quad$ pressure, $\mathrm{Pa}$

$\operatorname{Pr} \quad$ Prandtl number, $\operatorname{Pr}=\frac{C_{p, l} \mu_{l}}{k_{l}}$

$\mathrm{P}_{\text {rec }} \quad$ receiver power, $\mathrm{W}$

$\mathrm{r} \quad$ tank wall radius, $\mathrm{m}$

$\operatorname{Re} \quad$ Reynolds number, $\operatorname{Re}=\frac{\rho_{l} u d}{\mu_{l}}$

$\mathrm{t}$ time, $\mathrm{s}$

T temperature, ${ }^{\circ} \mathrm{C}$

$\mathrm{u} \quad$ velocity, $\mathrm{m} / \mathrm{s}$

$\mathrm{U} \quad$ overall heat transfer coefficient, $\mathrm{W} / \mathrm{m}^{2}-\mathrm{K}$

v heat-exchange region velocity, $\mathrm{m} / \mathrm{s}$ 


$$
\begin{aligned}
& \text { W gross turbine output, W } \\
& \text { x axial location, - } \\
& \text { y } \quad \text { steam fraction for deaeration, - }
\end{aligned}
$$

\section{Greek}
$\varepsilon \quad$ porosity, -
$\varepsilon_{\text {tank }} \quad$ storage effectiveness, -
$\eta \quad$ efficiency, -
$\mu \quad$ viscosity, $\mathrm{kg} / \mathrm{m}-\mathrm{s}$
$\rho \quad$ density, $\mathrm{kg} / \mathrm{m}^{3}$
$\Theta \quad$ non-dimensional temperature, -

\section{Subscript}

$\begin{array}{ll}\text { c } & \text { rated condition } \\ \text { eff } & \text { effective } \\ \text { h } & \text { hot } \\ \text { heel } & \text { liquid heel } \\ \text { HX } & \text { power block heat exchangers } \\ \text { in } & \text { inlet } \\ \text { init } & \text { initial } \\ \text { l } & \text { molten salt } \\ \mathrm{p} & \text { pump } \\ \text { rec } & \text { receiver } \\ \mathrm{s} & \text { solid filler }\end{array}$


$\mathrm{t}$ turbine

w wall

wat steam

$\mathrm{x} \quad$ axial location 
Table 1. Heat exchanger design data for the power block steam generators.

\begin{tabular}{cccc}
\hline Heat exchanger & Thermal power, $\mathbf{M W}$ & $\mathbf{U}, \mathbf{W} / \mathbf{m}^{\mathbf{2}} \mathbf{- K}$ & Area, $\mathbf{~ m}^{\mathbf{2}}$ \\
\hline Preheater & 57.34 & 1940 & 580.2 \\
Evaporator & 128.4 & 1392 & 1042 \\
Superheater & 85.12 & 911 & 849.8 \\
\hline
\end{tabular}


Table 2. Power block startup times for different turbine temperature states [20].

\begin{tabular}{cccc}
\hline $\begin{array}{c}\text { Hours after } \\
\text { shutdown }\end{array}$ & $\begin{array}{c}\text { Turbine } \\
\text { temperature }\end{array}$ & $\begin{array}{c}\text { Warming and } \\
\text { synchronization, min }\end{array}$ & $\begin{array}{c}\text { Ramp up, } \\
\text { min }\end{array}$ \\
\hline$<12$ & Hot & 15 & 25 \\
$12-72$ & Warm & 60 & 100 \\
$>72$ & Cold & 110 & 160 \\
\hline
\end{tabular}


Table 3. Comparison of annual energy output results for the $100 \mathrm{MW}$ power tower solar receiver and turbine from the current study and SOLERGY.

\begin{tabular}{ccc}
\hline Model & Solar receiver, $\mathbf{G W h}_{\mathbf{t}}$ & Turbine (net), $\mathbf{G W h}_{\mathbf{e}}$ \\
\hline Current study & 1281 & 465.4 \\
SOLERGY (thermocline) & 1326 & 476.4 \\
SOLERGY (two-tank) & 1326 & 476.4 \\
\hline
\end{tabular}




\section{List of Figures}

1. Schematic illustration of a molten-salt thermocline tank, including the porous quartzite rock bed and the pure liquid heel. Hot salt is supplied at the liquid heel through the top manifold and is extracted via the hot pump. Cold salt enters the porous bed through the bottom manifold but is also extracted through the manifold via the cold pump.

2. Temperature response of a $2.3 \mathrm{MWh}_{\mathrm{t}}$ molten-salt thermocline tank undergoing discharge. Numerical simulation is performed with two separate approaches: detailed computational fluid dynamics simulation, and a reduced-order finite volume method. Experimental temperature data reported for the tank [1] are also plotted for comparison.

3. Steam generator and steam Rankine cycle layout. LP is the low-pressure pump and HP is the high-pressure pump.

4. Temperature-entropy diagram of a steam Rankine cycle with non-reheat turbine and open feedwater heater for deaeration of the working fluid. The solid lines illustrate operation at rated turbine output, while the dashed lines illustrate operation at a minimum derated mode of $30 \%$ gross output.

5. Temperature plot of molten salt and steam inside power block heat exchangers. The solid lines illustrate the temperature response at rated operation; the dashed lines illustrate the temperature response at $30 \%$ derated operation.

6. Power tower plant performance for June $19-23$. Solar receiver power and gross turbine output are plotted on the left y-axis; energy stored in the thermocline tank is plotted on the right $y$-axis. The inclusion of the thermocline tank sustains power production each day after nighttime shutdown of the solar receiver. Step decreases in the receiver power 
correspond to energy saturation of the thermocline tank and consequent heliostat defocusing.

7. Power plant capacity factors observed for each month of operation. The solid line illustrates the plant performance with the thermocline tank; the dashed line illustrates the plant performance without the inclusion of any thermal energy storage.

8. Monthly thermocline storage performance and plant thermal energy discard. Discard is normalized with respect to the amount of sunlight available for collection each month. 